\title{
Comment on 'lonospheric signatures of dayside magnetopause transients: A case study using satellite and ground measurements' by Denig et al.
}

Article

Published Version

Lockwood, M. and Cowley, S. W. H. (1994) Comment on 'Ionospheric signatures of dayside magnetopause transients: A case study using satellite and ground measurements' by Denig et al. Journal of Geophysical Research, 99 (A3). pp. 42534255. ISSN 0148-0227 doi: https://doi.org/10.1029/93JA02737 Available at https://centaur.reading.ac.uk/38818/

It is advisable to refer to the publisher's version if you intend to cite from the work. See Guidance on citing.

Published version at: http://dx.doi.org/10.1029/93JA02737

To link to this article DOI: http://dx.doi.org/10.1029/93JA02737

Publisher: American Geophysical Union

All outputs in CentAUR are protected by Intellectual Property Rights law, including copyright law. Copyright and IPR is retained by the creators or other copyright holders. Terms and conditions for use of this material are defined in the End User Agreement. 


\section{CentAUR}

Central Archive at the University of Reading

Reading's research outputs online 


\title{
Comment on "Ionospheric signatures of dayside magnetopause transients: A case study using satellite and ground measurements" by Denig et al.
}

\author{
M. Lockwood \\ Rutherford Appleton Laboratory, Chilton, United Kingdom \\ S. W. H. Cowley \\ Blackett Laboratory, Imperial College, London, United Kingdom
}

\section{Introduction}

In their paper, Denig et al. [1993] (hereafter referred to as DEA) present a case study of some dayside auroral transients, using optical observations from the ground with in situ data from several Defense Meteorological Satellite Program (DMSP) satellites. Their primary conclusion is that the contribution of these events to the total ionospheric convection is small, contrary to recent findings for different events by Lockwood et al. [1990a].

In this comment, we do not necessarily take issue with this conclusion for the particular events DEA discuss. This is because these events were small and would not have elicited much attention, were it not for the timing of the pass of the DMSP F9 satellite. However, there are some considerations which do cast DEAs' estimates doubt, even for these events, and they are raised here in section 3 . The main point of this comment, discussed in section 2 , is that we believe the reasoning employed by DEA to be incorrect and that this is an important point of principle. Also, in section 4, we clear up the exact nature of the "suggestion" which DEA attribute to Lockwood et al. [1990b].

The last paragraph of the conclusion by DEA is curious and shows a need to clarify terminology. Having concluded that the putative Flux Transfer Event (FTE) signatures are insignificant, DEA (p. 5979) state "The concept of continuous or quasi-steady merging which is varying both temporally and spatially is more applicable for the present auroral activity." However, because it refers to the transfer of magnetic flux from the closed to the open regions, the term flux transfer event is synonymous with a "a pulse of enhanced magnetopause reconnection." (Note that DEA use the term "merging", whereas we prefer "magnetopause reconnection", thereby retaining Dungey's original terminology [Dungey, 1953] which is employed in all other branches of plasma physics). Hence the periods of enhanced reconnection during temporally-varying continuous reconnection are, by definition, FTEs. (Some scientists do not believe that the characteristic field and particle signatures at the magnetopause, also termed FTEs, are really due to pulses of enhanced magnetopause reconnection, but that is an entirely separate issue). The question that Lockwood et al. [1990a] were addressing is this: "how much do FTEs

Copyright 1994 by the American Geophysical Union.

Paper number 93JA02737.

0148-0227/94/93JA-02737\$05.00

contribute to convection?", which can equivalently be stated as "how variable is the magnetopause reconnection voltage?". Note therefore if we refer to reconnection being entirely pulsed, this means that FTEs are the dominant contribution to convection (the only other being the small viscous-like voltage). Only in this limit of the general behavior does the reconnection cease to be continuous. Smith et al. [1992] have stressed that steady and entirely pulsed reconnection are simply two limits of general reconnection behavior.

\section{The Evaluation of the Importance of FTEs To Convection}

DEA measure the potential across three transient arc fragments seen in the 557.7-nm auroral light. They do this by integrating the along-track electric field (corresponding to the cross-track drift), as measured by the DMSP F9 satellite, across the extent of these arc fragments. They find that these three voltages are smaller, by a factor of about 20 , than the total transpolar voltage measured, $20 \mathrm{~min}$. earlier in the other hemisphere, by the DMSP F8 satellite.

Because the F9 satellite is moving roughly northward (in geomagnetic coordinates - see their Figure 1), the voltages DEA quote are associated with east-west flows in the ionosphere. These east-west flows are caused by the magnetic "tension" force on newly opened field lines and are the F region flow equivalent of the Svalgard-Mansurov effect in $E$ region currents [Atkinson, 1972; Jorgenson et al., 1972; Cowley, 1981]. The magnitude of this east-west flow, and therefore the magnitude of the voltage estimates by DEA, depend upon the IMF $B_{y}$ component (which is not known in this case). It is important to note therefore that these voltages would fall to zero if that component were to be zero. In other words, for $B_{y}=0$, DEA would observe no voltage across the events, even were the dayside reconnection to have been entirely pulsed.

Lockwood et al. [1990b] make the point that it is not the instantaneous flow voltage which is relevant when evaluating the importance of FTEs to convection. Rather, the relevant voltage is the rate at which open flux is added to the polar cap by the reconnection bursts. If additional open magnetic flux $F$ (in Webers) is produced by a reconnection pulse (FTE) lasting $\delta t$ (seconds), the reconnection voltage during that pulse is $F / \delta t$ (volts). However, the contribution of such events to the average rate at which flux is opened is $F / \tau$, where $\tau$ is the event repetition period. Averaged over substorm cycles, this average magnetopause reconnection rate 
will equal the average value of the transpolar voltage, that is, steady state concepts apply on these time scales (see discussion by Lockwood and Cowley [1992]). The evolution of the flow following an isolated pulse of magnetopause reconnection (i.e., the ionospheric flow signature of an FTEs) has been discussed by Cowley et al. [1991] and Smith et al. [1992], allowing for the inductive smoothing of the ionospheric flow. A series of such pulses, sufficiently close together in time (of the order of $5 \mathrm{~min}$ ), would excite relatively steady dayside flow for $B_{y}$ approximately equal to zero.

We note, in passing, that the concept used by DEA of subtracting a background value from the flow voltage (associated with an FTE signature at any one instant) is not appropriate. This is because the motion of an FTE signature is set by the IMF strength and orientation, the solar wind speed and the ionospheric drag. Any background reconnection rate (between the pulses) will not cause the ionospheric FTE signature to move faster.

\section{An Alternative Explanation of the Events Presented by DEA}

Given the general principle outlined in section 2, it is not of great importance whether or not the particular events reported by DEA are, in fact, greater contributors to the overall convection pattern than they estimate. However, we note that the 557.7-nm transient seen $5 \mathrm{~min}$ before the three fragments studied by DEA is a considerably clearer and larger event. In addition, given that the important voltage is the average "flux addition rate" $(F / \tau)$, as described in the previous section, it is important to estimate the full area of each ionospheric event, $\mathrm{A}$, from which we can calculate the added flux $F=B_{1} A$, because the ionospheric field $B$ is effectively constant.

DEA only consider the three arc fragments where there is significant 557.7-nm emission. In all dayside transient events for which simultaneous ion drift measurements were made by the EISCAT radar, the 557.7-nm emissions were found to be in the region of upward field-aligned current of the oppositely directed pair required to transfer the flow burst momentum to the ionosphere [Sandholt et al., 1990; Lockwood et al., 1993a]. This means that DEA may be considering three filamentary upward field line currents on the edge of an FTE signature, rather than an FTE signature itself. Because the events move westward, the 557.7-nm emission would be on the poleward edge of the region of newly opened flux. We would expect such a region of newly opened flux to be filled with soft magnetosheath electron precipitation (cusp), which would give 630-nm aurorae with only very low levels of 557.7-nm emission [Cowley et al., 1991]. Such a region is reported equatorward of the 557.7-nm arc fragments, but is described by DEA as a "stable" background 630-nm arc. However, inspection of DEA's Figure 2 shows that this arc is not stable, in that it forms around 0725 UT (just 5 min before the 557.7-nm transients) while what previously was the "background" arc moves poleward in a transient event. Similar behavior is observed in other westward traveling events and was explained by Lockwood et al. [1990a] as being due to the dominantly $630-\mathrm{nm}$ transient (the region of newly opened flux) being more extensive (in both longitude and latitude) than the dominantly 557.7-nm emissions (the region of upward field-aligned current). As a result of its greater longitudinal extent, the enhanced $630-\mathrm{nm}$ emission arrives at the observed meridian before the 557.7-nm transient. Note that the $630-\mathrm{nm}$ emissions which DEA report in the same locations as the 557.7-nm arc fragments will be the few unquenched red-line emissions which must accompany the 557.7-nm emission. These emissions arise from the shortest of the distribution of radiative lifetimes of the excited metastable ${ }^{1} \mathrm{D}_{2}$ state of atomic oxygen atoms. (The average of this distribution is $110 \mathrm{~s}$, but a few emissions will occur almost immediately after a 557.7-nm emission has left that atom in the ${ }^{1} \mathrm{D}_{2}$ state and before it collides).

Were we therefore to consider the region of newly opened flux to appear at the Ny Ålesund meridian at 0725 UT (the onset of the $630-\mathrm{nm}$ transient), and its centre (with the peak upward field-aligned current and associated 557.7-nm aurora) to reach this meridian at 0730 , the mean westward flow speed seen by F9 (about $1 \mathrm{~km} \mathrm{~s}^{-1}$ ) yields an east-west extent of the event of $600 \mathrm{~km}$. Using the $200 \mathrm{~km}$ north-south extent of the "stable" arc reported by DEA, we would then estimate the total newly opened flux in the event to be $6 \times 10^{6} \mathrm{~Wb}$. Given that Figure 2 of DEA shows a clear prior event commencing at about 0722 , this gives a repetition period of $\tau=3 \mathrm{~min}$ and a contribution to convection of $33 \mathrm{kV}$. This is a much more significant fraction of the flux transfer rate across the central polar cap (i.e., the transpolar voltage) observed by F8 than was estimated by DEA. Note also that, at any one instant, the transpolar voltage and the magnetopause flux transfer rate are not generally equal: the former will be the larger if the sunward half of the polar cap was contracting in size during the interval $\tau$ over which the average dayside reconnection voltage $(F / \tau)$ was estimated [Lockwood and Cowley, 1992].

\section{What is Suggested About FTEs as a Source of Convection?}

DEA cite a paper by Lockwood et al. [1990b] as the origin of the suggestion that FTEs are a dominant contribution to convection. In fact, this paper deals with the two-source nature of ionospheric convection (driven by magnetopause reconnection and reconnection in the central current sheet of the geomagnetic tail), as revealed by the two response times of convection to changes in the IMF $B_{z}$ component. No such suggestion was made in this paper. However, in another paper (not cited by DEA), Lockwood et al. [1990a] did estimate the "average flux-addition rate" $(F / \tau)$ associated with auroral transients and flow bursts seen by the EISCAT radar. These voltages were considerable $(25-50 \mathrm{kV})$ and hence the concept put forward by these authors (that these events were a major contributor to ionospheric convection) was only a "suggestion," mainly because measurements of the average transpolar voltage were not actually available to us. Note that in these cases the IMF $B_{y}$ component was strongly positive and, as a result, very large flow voltages were seen across each of the FTE signatures (up to $80 \mathrm{kV}$ ). The dominantly 557.7-nm transients were always on the poleward edges of these events, coincident with the inferred upward fieldaligned current [Sandholt et al., 1990; Lockwood et al., 1993a].

The discussion in section 3 employs the area, A, of patches in the ionosphere which have been inferred (because of their pattern of motion and the soft electron precipitation) to be newly opened flux. The uncertainties with these 
estimates arise from the complex three-dimensional structure of the $630 \mathrm{~nm}$ auroral emissions and the limited field-of-view (instrument sensitivity falls rapidly at large zenith angles) [Lockwood et al., 1993a]. Full solution of such problems requires tomographic optical techniques over an extended range of longitudes and high-time-resolution convection measurements over a two-dimensional grid of locations. Nevertheless, we believe that the method has already shown that dayside transients can, at least sometimes, be a significant, and possibly the dominant contribution to convection [Lockwood et al., 1990a; 1993a].

Lastly, we point out that this conclusion has also been reached using an entirely independent technique. Lockwood and Smith [1992] have used cusp ion spectrograms to show that the dayside reconnection is sometimes entirely pulsed, that is, that the only reconnection taking place at one point on the magnetopause was in a series of discrete pulses. This condition has also been shown to be associated with poleward moving transient ionospheric electron temperature enhancements [Lockwood et al., 1993b]. These would give rise to poleward moving $630-\mathrm{nm}$ transients, detectable at winter solstice, because of the thermal excitation of the ${ }^{\prime} D_{2}$ state of atomic oxygen by the hot tail of the heated ionospheric electron gas (see discussion by Lockwood et al. [1993a]).

\section{References}

Atkinson, G., Magnetospheric flows and substorms, in Magnetosphere-Ionosphere Interactions, edited by $\mathbf{K}$. Folkestadt, p. 203, Universitetsforlaget, Oslo, Norway, 1972.

Cowley, S.W.H., Magnetospheric asymmetries associated with the Y-component of the IMF. Planet Space Sci., 29, 79, 1981.

Cowley, S.W.H., M.P. Freeman, M. Lockwood, and M.F. Smith, The ionospheric signature of flux transfer events, in CLUSTER - dayside polar cusp, edited by. C.I. Barron, p.105, ESA SP-330, European Space Agency Publications, Noordwijk, Netherlands, 1991.

Denig, W.F., W.J. Burke, N.C. Maynard, F.J. Rich, B. Jacobsen, P.E. Sandholt, A. Egeland, S. Leontiev, and V.G. Vorobjev, Ionospheric signatures of dayside magnetopause transients: A case study using satellite and ground measurements, J. Geophys. Res., 98, 5969, 1993.

Dungey, J. W., Conditions for the occurrence of electrical discharges in astrophysical systems, Philos. Mag., 44, 725, 1953.
Jørgenson, T.S., E. Friis-Christensen, and J. Wilhjelm, Interplanetary magnetic direction and high latitude ionospheric currents, J. Geophys. Res., 77, 1976, 1972.

Lockwood, M., and S.W.H. Cowley, Ionospheric Convection and the substorm cycle, in Substorms 1, Proceedings of the First International Conference on Substorms, ICS1, edited by C. Mattock, p. 99, ESA-SP-335, European Space Agency Publications, Noordwijk, The Netherlands, 1992.

Lockwood, M., and M.F. Smith, The variation of reconnection rate at the dayside magnetopause and cusp ion precipitation, J. Geophys. Res., 97, 14,841, 1992.

Lockwood, M., P.E. Sandholt, and S.W.H. Cowley, Dayside auroral activity and magnetic flux transfer from the solar wind, Geophys. Res. Lett., 16, 33, 1989.

Lockwood, M., S. W. H. Cowley, P. E. Sandholt, and R. P. Lepping, The ionospheric signatures of flux transfer events and solar wind dynamic pressure changes, J. Geophys. Res., 95, 17,113, 1990a.

Lockwood, M., S.W.H. Cowley, and M.P. Freeman, The excitation of plasma convection in the high latitude ionosphere, J. Geophys. Res., 95, 7961, 1990b.

Lockwood, M., H.C. Carlson, and P.E. Sandholt, The implications of the altitude of transient $630 \mathrm{~nm}$ dayside auroral emissions, J. Geophys. Res., 98, 15,571, 1993a.

Lockwood, M., W.F. Denig, A.D. Farmer, V.N. Davda, S.W.H. Cowley, and H. Luhr, Ionospheric signatures of pulsed magnetic reconnection at the Earth's magnetopause, Nature, 36l(6411), 424, 1993b.

Sandholt, P.E., M. Lockwood, T. Oguti, S.W.H. Cowley, K.S.C. Freeman, A. Egeland, B. Lybekk, and D.M. Willis, Midday auroral breakup events and related energy and momentum transfer from the magnetosheath, J. Geophys. Res., 95, 1039, 1990.

Smith, M.F., M. Lockwood, and S.W.H. Cowley, The statistical cusp: A simple flux transfer event model Planet. Space Sci., 40, 1251, 1992.

S.W.H. Cowley, Blackett Laboratory, Imperial College, London, SW7 2BZ, UK. (e-mail: SPAN 19773::cowley)

M. Lockwood, Rutherford Appleton Laboratory, Chilton, Didcot, OX11 0QX, UK. (e-mail: mike@eiscat.ag.rl.ac.uk)

(Received July 8, 1993; revised September 17, 1993; accepted September 17, 1993) 